\title{
Erratum to: Chronic Granulomatous Disease: A 25-Year Patient Registry Based on a Multistep Diagnostic Procedure, from the Referral Center for Primary Immunodeficiencies in Greece
}

\author{
Maria Raptaki • Ioanna Varela - Kleopatra Spanou - Marianna Tzanoudaki • \\ Sofia Tantou • Manolis Liatsis • Nikki Constantinidou • Chryssa Bakoula • \\ Dirk Roos • Maria Kanariou
}

Published online: 26 September 2014

(C) Springer Science+Business Media New York 2014

Erratum to: J Clin Immunol (2013) 33:1302-1309

DOI 10.1007/s10875-013-9940-z

The authors report that the abstract contains an error. The fifth sentence should have appeared as follows: Sixteen patients from 14 unrelated families had X-linked CGD $(66.7 \%)$, four had mutations in the NCF1 gene (19\%), and three, from two unrelated families, had mutations in NCF2 (9.5\%). The error does not affect the integrity of the data or study conclusions. The authors regret the error.

The online version of the original article can be found at http://dx.doi.org/ 10.1007/s10875-013-9940-z.

\footnotetext{
M. Raptaki $\cdot$ I. Varela $\cdot$ K. Spanou $\cdot$ M. Tzanoudaki $\cdot$ S. Tantou $\cdot$

M. Liatsis $\cdot$ N. Constantinidou $\cdot$ M. Kanariou $(\triangle)$

Department of Immunology - Histocompatibility, Specialized

Center \& Referral Center for Primary Immunodeficiencies

-Paediatric Immunology, “Aghia Sophia” Children's Hospital,

Athens, Greece

e-mail:m.kanariou@gmail.com

C. Bakoula

Second Department of Paediatrics, University of Athens,

"P \& A Kyriakou" Children's Hospital, Athens, Greece

D. Roos

Department of Blood Cell Research, Sanquin Research, and Landsteiner Laboratory, Academic Medical Centre,

University of Amsterdam, Amsterdam, The Netherlands 